\title{
Nutrient dynamics along the Moskva River under heavy pollution and limited self- purification capacity
}

\author{
Maria Tereshina*, Oxana Erina, Dmitriy Sokolov, Lyudmila Efimova, and Nikolay \\ Kasimov \\ Lomonosov Moscow State University, Faculty of Geography, GSP-1, 1 Leninskiye Gory, 119991, \\ Moscow, Russia
}

\begin{abstract}
An extensive study conducted during the dry summer of 2019 provided a detailed picture of the nutrient content dynamics along the Moskva River. Water sampling at 38 locations on the main river and at 17 of its tributaries revealed a manifold increase in phosphorus and nitrogen concentrations as the river crosses the Moscow metropolitan area, which can be attributed to both direct discharge of poorly treated sewage and nonpoint urban pollution. Even at the Moskva River lower reaches, where the anthropogenic pressure on the river and its tributaries is less pronounced, the inorganic nitrogen and phosphorus content remains consistently high and exceeds the environmental guidelines by up to almost 10 times. This indicates increased vulnerability of the Moskva River ecosystem during periods of low flow, which can be a major factor of eutrophication in the entire Moskva-Oka-Volga system. Comparison of our data with some archive records shows no significant improve in the nutrient pollution of the river since the 1990s, which raises further concern about the effectiveness of water quality management in Moscow urban region.
\end{abstract}

\section{Introduction}

Anthropogenic nutrient pollution has been considered one of the world's major environmental problems for decades [1]. Excessive nutrient loading leads to eutrophication of lakes and streams, increasing the risk of harmful algal blooms, causing damage to aquatic ecosystems and impairing water treatment [2]. Modern scientific basis suggests that the regulation of both nitrogen and phosphorus, especially their dissolved mineral forms, is essential for anthropogenic eutrophication control [3]. This idea, as well as the concern about their overall toxicity, is implemented throughout the world in the form of environmental guidelines that set their maximum permissible content in water [4].

For the rivers of the Central Russia, a lot of environmental risks come from an inefficient infrastructure of water supply and treatment systems, especially in urban areas, but limited availability of water quality information impedes detection of specific pollution

\footnotetext{
*Corresponding author: martereshina@yandex.ru
} 
sources and control over them [5]. The Moskva River basin is a striking example of this: multiple studies show that the Moskva River plays a major role in the pollution of the Oka and Volga rivers (including their nutrient pollution) [6-8], but low spatial coverage, scarcity and poor accessibility of its environmental monitoring data hinder comprehensive research.

In August 2019, we conducted an extensive study of hydrology and water chemistry in the Moskva River basin, which provided a detailed picture of the longitudinal dynamics of the water quality in the Moskva River itself and helped to outline specificities of its main tributaries. The extremely dry summer of 2019 caused some pollutant concentrations, including nitrogen and phosphorus, to reach extreme values, which raises the concern about increasing vulnerability of the Moskva, Oka and Volga ecosystems during low flow periods, when the rivers' dilution and self-purification capacity are heavily restricted.

\section{Materials and methods}

To better examine all the longitudinal changes in the nutrient content of the Moskva River, we sampled the water at 38 points along the river's length over 3 days (August 6-8, 2019). The sampling was carried out downstream from major population centers on the river, its major tributaries and dams (Fig. 1). All of the 17 marked tributaries were also sampled at a small distance from their confluence with the Moskva River, as well as the outlet of the Lyubertsy wastewater treatment plant, which releases a major part of treated sewage from the Moscow City.

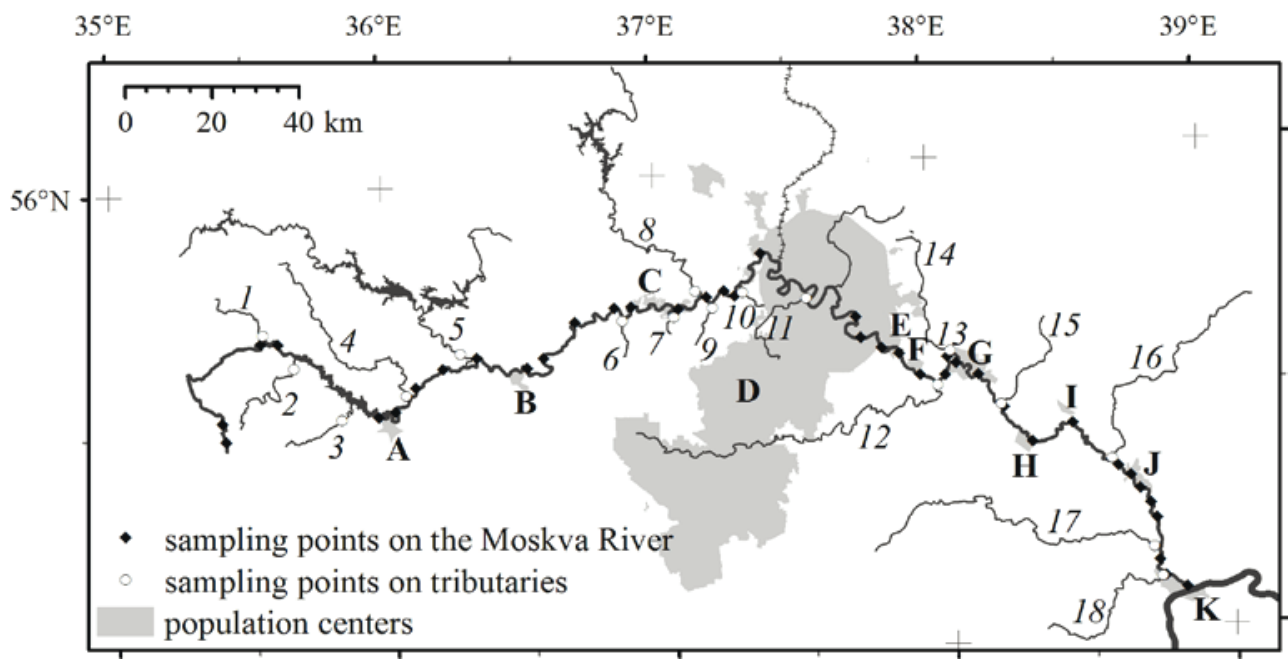

Fig. 1. The Moskva River basin. Water sampling points on the tributaries: 1 - Inoch, 2 - Lusyanka, 3 - Koloch, 4 - Iskona, 5 - Ruza, 6 - Nahavnya, 7 - Vyazemka, 8 - Istra, 9 - Medvenka, 10 Chachenka, 11 - Setun, 12 - Pahra, 13 - discharge from the Lyubertsy sewage treatment plant, 14 Pehorka, 15 - Gzhelka, 16 - Nerskaya, 17 - Severka, 18 - Kolomenka. Population centers: A Mozhaysk, B - Tuchkovo, C - Zvenigorod, D - Moscow, E - Dzerzhinsky, F - Lytkarino, G Zhukovskiy, H - Bronnitsy, I - Beloozerskiy, J - Voskresensk, K - Kolomna.

In all of the samples, the total and inorganic phosphorus content were determined using the Murphy-Riley method [9], their dissolved fractions were determined the same way after filtration through a $0.45 \mu \mathrm{m}$ membrane filter. Total and dissolved nitrogen content were determined via alkaline per sulphate digestion [10]. Nitrate and ammonia nitrogen concentrations were measured using the ion chromatography method, and nitrite concentration was measured by Griess method [10]; all of the nitrogen species were determined in filtered samples only. 
Environmental guidelines for nutrient content used here are the maximum acceptable concentrations set by the Ministry of Agriculture of the Russian Federation.

\section{Results and discussion}

In its upper reaches, the Moskva River contained relatively low amounts of nutrient elements (Fig. 2): upstream from the Mozhaysk Reservoir, typical total phosphorus (TP) concentrations were within $0.03-0.05 \mathrm{mg} / \mathrm{L}$, total nitrogen $(\mathrm{TN})-0.4-0.8 \mathrm{mg} / \mathrm{L}$. Phosphate content (at dissolved inorganic phosphorus, DIP) did not exceed $0.02 \mathrm{mg} / \mathrm{L}$, total inorganic nitrogen (TIN) content was within $0.1-0.3 \mathrm{mg} / \mathrm{L}$ with ammonia nitrogen as a predominant form. Slightly higher nutrient content was registered at the very source of the river: TP value at the highest point on the river reached $0.12 \mathrm{mg} / \mathrm{L}, \mathrm{TN}-2.75 \mathrm{mg} / \mathrm{L}$, which is explained by a high organic matter input from the wetland at the river's source that is quickly diluted by further runoff.
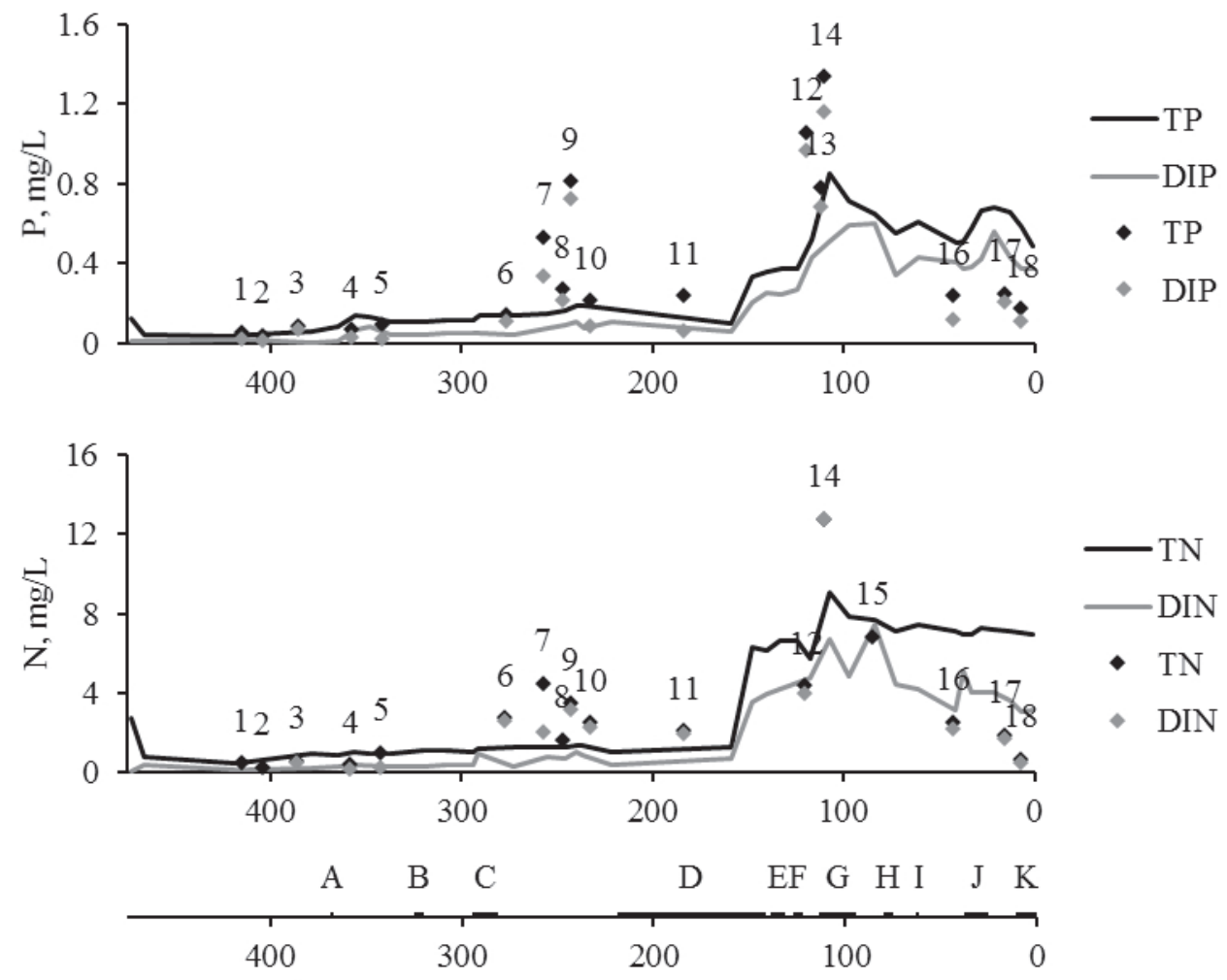

distance from the Moskva River mouth, $\mathrm{km}$

Fig. 2. Concentrations of total (TP) and dissolved inorganic (DIP) phosphorus total (TN) and dissolved inorganic (DIN) nitrogen in the Moskva River (lines) and its tributaries (dots); distribution of the population centres along the course of the Moskva River. For tributary and town identification - see caption for Fig. 1.

A slight shift in the nutrient content and composition was noted below the Mozhaysk Reservoir - the largest reservoir on the Moskva River - with the proportion of organic phosphorus reaching over $90 \%$ and a two-fold increase in total and suspended nitrogen, but these changes are quickly balanced out downstream. 
Between Mozhaysk and Moscow, the total nutrient content of the Moskva River gradually increased by 1.5-3 times: by the upper Moscow City limit, the TP and TN values reach $0.19 \mathrm{mg} / \mathrm{L}$ and $1.3 \mathrm{mg} / \mathrm{L}$, respectively. At this section of the river, phosphate contributed to about a half of TP content, mineral nitrogen proportion varied from about 30 to $80 \%$ with a continuous prevalence of nitrate among its mineral forms. Downstream from Zvenigorod and down to the river mouth, the nitrite nitrogen concentrations are persistently higher than the Russian environmental guideline $(0.02 \mathrm{mg} / \mathrm{L})$.

Some of the smaller streams that join the Moskva before the Moscow City already show extremely high nutrient levels, especially small right-side tributaries Vyazemka (TP 0.53 $\mathrm{mg} / \mathrm{L}, \mathrm{TN} 4.47 \mathrm{mg} / \mathrm{L}, \mathrm{NO}_{2}-\mathrm{N} 0.12 \mathrm{mg} / \mathrm{L}$ ) and Medvenka (TP $0.81 \mathrm{mg} / \mathrm{L}, \mathrm{TN} 3.5 \mathrm{mg} / \mathrm{L}$, $\mathrm{NO}_{2}-\mathrm{N} 0.09 \mathrm{mg} / \mathrm{L}$ ), but due to their small water discharge and the Moskva River's sufficient dilution and self-purification capacity, it only slightly affects the main river.

As the Moskva River flows through the Moscow City, water nutrient concentrations experience a manyfold increase. At the eastern part of the city, TP exceeded $0.3 \mathrm{mg} / \mathrm{L}$ and $\mathrm{TN}-0.6 \mathrm{mg} / \mathrm{L}$. From this part of the river, a steady prevalence of dissolved inorganic forms of both elements occurs: about $80 \%$ of total phosphorus, and almost all of the nitrogen is dissolved, which is typical for urban wastewater. At the lower city limit, environmental guidelines for almost all of the mineral nutrient forms (phosphate -0.2 $\mathrm{mgP} / \mathrm{L}$, nitrite $-0.02 \mathrm{mgN} / \mathrm{L}$, ammonia $-0.4 \mathrm{mgN} / \mathrm{L}$ ) are exceeded and do not go back to acceptable levels until the river's mouth. Although a large portion of mineral nitrogen is presented by nitrates, ammonia nitrogen becomes to slightly prevail again as the river's oxidization capability becomes insufficient because of an extremely high contaminant load: the water oxygen saturation here drops down to $70-80 \%$.

As most of the treatment plant outlets are located outside of the city limits, nutrient content continues to increase after the river passes Moscow. As was expected, maximum $\mathrm{TP}$ and $\mathrm{TN}(0.85$ and $9.1 \mathrm{mg} / \mathrm{L}$, respectively) concentrations were observed below the Lyubertsy wastewater treatment plant. DIP content $(0.51 \mathrm{mg} / \mathrm{L})$ exceeded the guideline by a factor of 2.6, ammonium nitrogen $(3.6 \mathrm{mg} / \mathrm{L})$ - by 9 times, nitrite nitrogen $(0.33 \mathrm{mg} / \mathrm{L})$ - by over 15 times.

Some of the tributaries that join the Moskva River below city limits and receive some or most of their water inflow from densely populated and highly industrially developed areas have even higher levels of nutrient pollution. In the relatively large Pehorka River, the nutrient content was the highest among the streams covered in this study with TP concentration of over $1.3 \mathrm{mg} / \mathrm{l}$ and almost $13 \mathrm{mg} / \mathrm{L}$ of TN. Pehorka, Pahra and Gzhelka further increase the Moskva's nutrient load.

At some distance from Lyubertsy, nutrient concentrations in the Moskva River somewhat decrease, but nitrogen and phosphorus levels stay extremely high. TP value stays within the range of $0.49-0.67 \mathrm{mg} / \mathrm{L}$ for the remaining length of the river, TN $-6.9-7.3$ $\mathrm{mg} / \mathrm{L}$. A significant increase is observed below Voskresensk, but in general the nutrient content remains almost unaltered. The much less polluted tributaries of the lower part of the Moskva basin, even relatively large streams, only to some extent contribute to the main river's self-purification.

Although chemical oxidization and biological activity help transform some of the nutrients into more biologically available forms, an overwhelming part of nutrients is not assimilated by biota, and at its final point the Moskva River still unloads a huge deposit of inorganic nutrient matter into the Oka River.

At the lower reaches, oxygen saturation in the Moskva River exceeded 100\% again because of increased photosynthetic activity and atmospheric exchange. The ongoing nitrification process restored the predominance of nitrates in the inorganic nitrogen load, but caused persistent nitrite accumulation in the river: the nitrite nitrogen concentration stayed at the level of about $0.2 \mathrm{mg} / \mathrm{L}$ throughout the last $60 \mathrm{~km}$ of the river's course. This 
indicates that the urban pollution from the Moscow metropolitan area does not only cause anthropogenic eutrophication of the Moskva River and the Oka-Volga system, but also contributes to its overall toxicity.

Comparison to the historical data on the summer water chemistry of the Moskva River over 1970s - late 90s (as summarized in [11]) shows that in August 2019 the inorganic nitrogen and phosphorus content at the upper reaches (downstream from the Mozhaysk Dam) was significantly lower than normal, but their concentrations at the lower Moscow City limit and at the river mouth were close to those usually observed in earlier years (Table 1). No positive development in wastewater treatment and pollution management in the Moskva River basin over the last two and a half decades is therefore discovered.

Table 1. Comparison of archived and our data on inorganic nitrogen content $(\mathrm{mg} / \mathrm{L})$ in the Moskva River at various sites.

\begin{tabular}{|c|c|c|c|c|c|c|}
\hline & \multicolumn{2}{|c|}{$\begin{array}{c}\text { Downstream of } \\
\text { Mozhaysk }\end{array}$} & \multicolumn{2}{c|}{$\begin{array}{c}\text { Downstream of Moscow } \\
\text { and Lyubertsy }\end{array}$} & \multicolumn{2}{c|}{ Moskva River mouth } \\
\hline & $\mathbf{1 9 7 3 - 1 9 9 7}[\mathbf{1 1}]$ & $\mathbf{2 0 1 9}$ & $\mathbf{1 9 7 3 - 1 9 9 7}[\mathbf{1 1}]$ & $\mathbf{2 0 1 9}$ & $\mathbf{1 9 7 3 - 1 9 9 7}[\mathbf{1 1}]$ & $\mathbf{2 0 1 9}$ \\
\hline $\mathrm{NH}_{4}-\mathrm{N}$ & $0.4-0.8$ & 0.11 & $3.9-6.8$ & 3.6 & $0.8-8.1$ & 0.9 \\
\hline $\mathrm{NO}_{2}-\mathrm{N}$ & $0.02-0.04$ & 0.002 & $0.20-0.41$ & 0.3 & $0.10-0.29$ & 0.19 \\
\hline $\mathrm{NO}_{3}-\mathrm{N}$ & $0.08-0.7$ & 0.11 & $1.4-8.3$ & 2.8 & $1.5-3.7$ & 2.1 \\
\hline
\end{tabular}

\section{Conclusion}

A detailed study of the nutrient dynamics along the course of the Moskva River clearly shows the damaging effect of the Moscow City region on the aquatic ecosystem. Total nitrogen and phosphorus content increase 5-7 times below the city limits as a result of insufficient wastewater management; environmental guidelines for almost all inorganic $\mathrm{N}$ and $\mathrm{P}$ forms are exceeded by up to 15 times. The general pattern of nutrient content change along the length of the river suggests both the presence of unchecked or non-point pollution and insufficient treatment of municipal sewage.

Within the city limits, the toxic effect of the excessive nutrient load is evident by a decreased photosynthetic activity and lowered water oxygen saturation. Even at the lower reaches of the Moskva River, a continuous accumulation of nitrite nitrogen is found, as well as extremely high phosphate and ammonia levels. Current water runoff and trophic state of the river system cannot provide adequate self-purification capacity for this high pollution level during low flow seasons. As a result, the urban effect of Moscow reaches far behind the Moscow Region and spreads to a larger scale.

Our data shows no significant improvement in nutrient contamination of the Moskva River since the 1970-s - 1990-s despite any reported upgrades in wastewater and water supply management.

The fieldwork for this study was supported by the Russian Geographical Society (project "The Moscow river from the headwaters to the mouth: hydrological and geochemical assessment of ecological state"). The methodology and design of the monitoring framework was developed with support of the Russian Science Foundation (project no. 19-77-30004).

\section{References}

1. C. J. Vörösmarty et al., Nature 467, 555-561 (2010)

2. R.W. Howarth et al., Issues Ecol. 7, 1-15 (2000)

3. W. M. Lewis jr., W.A. Wurtsbaugh, H.W. Paerl, Environ. Sci. Technol. 45, 10300 10305 (2011) 
4. R. Helmer, I. Hespanhol, WHO, Water Pollution Control: A Guide to the Use of Water Quality Management Principles (Taylor \& Francis, London, UK, 1997)

5. E. Nikitina, E. Ostrovskaya, M. Fomenko, Reg. Environ. Change 10, 285-297 (2010)

6. R.G. Dzhamalov, K.G. Vlasov, K.G. Myagkova, O.S. Reshetnyak, T.I. Safronova, Water Resour. 46, 74-84 (2019)

7. T. Gremm, A. Heidt, F. Frimmel, V. Yashin, A. Mytryukhin, V. Rainin, Water Resources Quality, 103-125 (Springer, Berlin, Heidelberg, 2002)

8. A.M. Nikanorov, V.A. Bryzgalo, G.M. Chernogaeva, Russ. Meteorol. Hydrol. 32, 698-710 (2007)

9. J. Murphy, J.P. Riley, Anal. Chim. Acta 27, 31-36 (1962)

10. L.M.L. Nollet, L.S.P. De Gelder, Handbook of Water Analysis (CRC Press, 2013)

11. V.A. Razumov, F.I. Tyutyunova, Water Resour. 28, 324-334 (2001) 